\title{
NOTE ON ARABIC NAMES AND TERMS
}

Whenever possible, I have tried to explain variations in the names of organizations depending on differences in translation styles. Sometimes the founders themselves chose names for their organizations not consistent with accurate translation. For example, Jamiiyat al-Nahḍah al-Filasțtinīyah, the Palestine (or Palestinian) Nationalist Renaissance Society, was named in English the Palestine National League by its founder, Fuad Shatara. Adding to the confusion is the dearth of archival evidence that obscures this society's reemergence as the Arab National League, causing some scholars to assume that each title belonged to a different organization. Some scholars offer their own translations if they come across names in Arabic, not to mention that translations may vary from one scholar to the next depending on his or her language skill.

I follow common practices of transliterating Arabic phonetics in that I minimize the use of symbols to denote Semitic sounds. I generally have not hyphenated names; for example, Abd-ul-Hamid and Abd-el-Hadi are spelled Abdulhamid and Abdelhadi or Abdulhadi unless quoted. Variations in a name's spelling do not change how it is pronounced. The name $\mathrm{Hu}-$ saini is often spelled Husseini or Husayni. I follow the spelling used in relevant citations, for instance, Mikhail Naimy as opposed to the standard Ar-

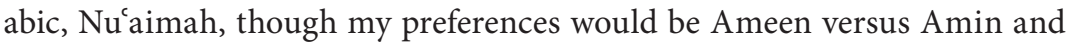
Muhammad versus Muhamed unless citing text. Some Arabic words conveniently connote concepts essential to the discussion. Most Arabic-language text I have used is transliterated in the notes and translated in text. 
THIS PAGE INTENTIONALLY LEFT BLANK 
THE MAKING OF ARAB AMERICANS 
THIS PAGE INTENTIONALLY LEFT BLANK 